\title{
Effects of annexin A1 on apoptosis and cell cycle arrest in human leukemic cell lines
}

\author{
AFFIDAH SABRAN ${ }^{1}$ \\ ENDANG KUMOLOSASI ${ }^{1 *}$ \\ IBRAHIM JANTAN ${ }^{2}$ \\ ${ }^{1}$ Drug and Herbal Research Centre \\ Faculty of Pharmacy, University \\ Kebangsaan Malaysia, Kuala Lumpur \\ Malaysia \\ 2 School of Pharmacy, Taylor's \\ University, Lakeside Campus, 47500 \\ Subang Jaya, Selangor, Malaysia
}

Accepted August 20, 2018

Published online September 16, 2018

\begin{abstract}
Recent studies suggest that annexin A1 (ANXA1) promotes apoptosis in cancerous cells. This study aims to investigate the effects of ANXA1 on apoptosis and cell cycle arrest in K562, Jurkat and U937 cells and peripheral blood mononuclear cells (PBMC). Cells were treated with ANXA1 and cyclophosphamide prior to flow cytometry analysis for apoptosis and cell cycle arrest induction. At $2.5 \mu \mathrm{M}$, ANXA1 induced significant apoptosis in K562 $(p \leq 0.001)$ and U937 $(p \leq 0.05)$ cells, with $E C_{50}$ values of 3.6 and $3.8 \mu \mathrm{M}$, respectively. In Jurkat cells, induction was not significant $\left(E C_{50}, 17.0 \mu \mathrm{M}\right)$. No significant apoptosis induction was observed in PBMC. ANXA1 caused cycle arrest in the G0/G1 phase in K562 and U937 cells with $p \leq 0.001$ for both, and $(p \leq 0.01)$ for Jurkat cells. ANXA1 induced apoptosis and cycle arrest in the G0/G1 phase in K562 and U937 cells, causing only cell cycle arrest in Jurkat cells.
\end{abstract}

Keywords: annexin A1, apoptosis, cell cycle, flow cytometry, human leukemic cell lines

Leukemia is a hematopoietic system malignant proliferative disease $(1,2)$. Like other cancerous diseases, it is characterized by the inability of hematopoietic stem cells (HSC) to undergo apoptosis and cycle arrest, resulting in uncontrollable cell growth $(3,4)$. Leukemia is difficult to cure since it is a highly complex and multi-targeted disease in which current therapy is associated with severe toxicity and treatment-related death (5) the lack of molecular markers precludes minimal residual disease (MRD).

Annexin A1 (ANXA1) is a 37kDa protein, which belongs to the group of cellular proteins called Annexins. ANXA1 is either located in the cytosol or membrane bound in various types of cells (6). Initially described as glucocorticoid-inducible protein, it was previously known as lipocortin A1. It is a member of the Annexin family proteins and binds to calcium and phospholipids, giving rise to specific biological functions in membrane reorganization and intracellular regulation, such as down-regulation of inflammation $(7,8)$. As a phospholipid-binding protein, ANXA1 has been implicated in various intra- and extracellular functions, including inhibition of cyclooxygenase 2 (COX-2), phospholipase A2, signal transduc-

\footnotetext{
*Correspondence; e-mail address: e_kumolosasi@yahoo.co.id; e_kumolosasi@ukm.edu.my
} 
tion, DNA replication, cell transformation, ion channel formation, and mediation of cell proliferation, differentiation and apoptosis $(7,9,10)$. Ahmad et al. (2014) have shown that production of ANXA1 in PBMC can be induced by curcumin and phytoestrogens (11). ANXA1 has been vastly studied for its anti-inflammatory properties, but little is known about its anticancer effects, including its effect on leukemia. However, ANXA1 has been recently proposed to play a role in cancer cell apoptosis $(12,13)$. ANXA1 can affect many components of the inflammatory reaction besides the metabolism of arachidonic acid. Recent data have shown that ANXA1 may specifically target cytosolic PLA2 by both direct enzyme inhibition and suppression of cytokine-induced activation of the enzyme. ANXA1 inhibits the expression and/or activity of other inflammatory enzymes like inducible nitric oxide synthase (iNOS). It was suggested that the deregulation and subcellular localization of ANXA1 was involved in the development, invasion, metastasis, progression and drug resistance to a variety of cancers. The pattern of ANXA1 involvement in tumorigenesis, cell differentiation, proliferation and apoptosis was taken to be tissue-specific (14). Its expression has been reported to be increased in certain cancers, such as pancreatic and gastric cancers, but decreased in prostate, breast and esophageal cancers $(7,14)$.

Endogenous intracellular ANXA1 has been found to promote apoptosis in cells of myelomonocytic derivation (15). Over-expression of ANXA1 was shown to induce caspase-mediated apoptosis in macrophage cells (16). Hirata (2014) stated that ANXA1 has the ability to down-regulate the COX-2 pathways making it a possible molecular target for future anticancer treatment (17). Petrella et al. (2008) demonstrated that ANXA1 might also assist in histone deacetylase (HDAC) inhibitors' effect in inhibiting cell proliferation of three human leukemic cell lines, U937, K562 and Jurkat (18). Various studies have shown that the administration of exogenous recombinant ANXA1 plays a role in attenuating several diseases, such as Alzheimer's disease, restores cell polarity, cyctoskeleton integrity and paracellular permeability of cerebrovascular endothelial cells, attenuates STZ-induced diabetes, cardiac and renal dysfunction and mimics the improvement effect of mesenchymal stromal cells (MSCs) on islet cells function (19-22).

The present study aims to investigate the role of ANXA1 as an endogenous protein in leukemic cells. The effects of ANXA1 on leukemia were assessed in K562, Jurkat, and U937 leukemic cell lines by determining its effect on apoptosis and cell cycle arrest.

\section{EXPERIMENTAL}

\section{Reagents}

ANXA1 (Cat. No.: RPE787Hu01, USCNK, China), Cyclophoshamide (Endoxan, Germany), BD Pharmingen ${ }^{\mathrm{TM}}$ Annexin V-FITC (BD Bioscience, USA), Propidium iodide, PI (Sigma, USA), BD Cycletest ${ }^{\mathrm{TM}}$ Plus DNA Reagent Kit (Becton Dickinson, USA), methyl thiazolyltetrazolium, MTT (Sigma, USA), dimethyl sulfoxide, DMSO (Merck, Germany).

\section{Cell lines}

Chronic myelogenous leukemia (K562), acute lymphocytic leukemia (Jurkat) and acute myelogenous leukemia (U937) cell lines were purchased from the American Type Culture Collection (ATCC, USA). K562 cells were cultured in Iscove's Modified Dulbecco's 
Medium, IMDM (Gibco, USA) supplemented with $10 \%$ fetal bovine serum (FBS), $100 \mathrm{IU} \mathrm{mL}^{-1}$ penicillin and $100 \mu \mathrm{g} \mathrm{mL}^{-1}$ streptomycin. U937 and Jurkat cells were cultured in RPMI 1640 (Gibco, USA) supplemented with $10 \%$ FBS (Gibco), $100 \mathrm{IU} \mathrm{mL} \mathrm{m}^{-1}$ penicillin and $100 \mu \mathrm{g} \mathrm{mL}$ streptomycin (Amresco, USA).

\section{Isolation of peripheral blood mononuclear cells (PBMC)}

Blood was obtained from healthy donors $(n=3)$, aged 18 to 50 years, who participated in the study. The donors satisfied the inclusion criteria: were non-smokers, fasted overnight and did not take any medication or supplements. Written and informed consent was obtained from the participants prior to blood collection. The experimental protocol was approved by the UKM Human Ethical Committee (Approval No. UKM 1.5.3.5/244/NF-05015) and followed the principles outlined in the Declaration of Helsinki.

Blood samples were diluted with the same volume of RPMI 1640 media. Separation of blood cells was performed using density centrifugation. Briefly, the diluted blood sample was carefully layered on Lymphoprep ${ }^{\mathrm{TM}}$ (Axis-Shield, Norway) and the mixture was later centrifuged at $600 \times g$ for $20 \mathrm{~min}$ at $20^{\circ} \mathrm{C}$. The mononuclear cell layer was carefully separated. The PBMCs were washed twice with RPMI 1640 media and resuspended in RPMI-1640 media supplemented with $2 \mathrm{mM}$ L-glutamine, $100 \mathrm{IU} \mathrm{mL} \mathrm{mL}^{-1}$ penicillin, $100 \mu \mathrm{g} \mathrm{mL} \mathrm{m}^{-1}$ streptomycin and $10 \%$ FBS. The cell suspension was adjusted to approximately $5 \times 10^{5}$ cells $\mathrm{mL}^{-1}$.

\section{Enzyme-linked immunosorbent assay (ELISA) and quantification of ANXA1}

The cells were seeded at $5 \times 10^{5}$ cells $\mathrm{mL}^{-1}$ and incubated at $37^{\circ} \mathrm{C}$ for $24 \mathrm{~h}$. The extracellular ANXA1 were collected by centrifugation at $130 \times g$, at $25^{\circ} \mathrm{C}$ for $7 \mathrm{~min}$ for leukemic cell lines and at $300 \times g, 4^{\circ} \mathrm{C}$ for $10 \mathrm{~min}$ for PBMC. The cell pellet was resuspended and incubated in $200 \mu \mathrm{L}$ of phosphate-buffered saline (PBS) with $2 \mathrm{mM}$ ethylenediaminetetraacetic acid (EDTA) for $5 \mathrm{~min}$ at room temperature to collect the membrane-bound ANXA1. The cells were then centrifuged and the supernatants containing the membrane-bound ANXA1 were collected. RIPA lysis buffer $(200 \mu \mathrm{L})$ containing protease inhibitor was added to the cell pellet and the mixture was vortexed for $30 \mathrm{~s}$ before centrifugation at $13,000 \times \mathrm{g}$ for $15 \mathrm{~min}$ at $4{ }^{\circ} \mathrm{C}$ to collect the intracellular ANXA1. ANXA1 quantification was performed using an ANXA1 ELISA kit according to the supplied instructions.

\section{Cell viability assay}

Cell viability was assessed using the MTT assay according to the established procedure with minor modifications (23). Cells were seeded at a density of $2 \times 10^{5}$ cells $\mathrm{mL}^{-1}$ in a 96-well plate. The cells were then treated with ANXA1 and cyclophosphamide at concentrations ranging from $0-5 \mu \mathrm{M}$ and $0-28700 \mu \mathrm{M}$, respectively, and incubated for $24 \mathrm{~h}$ at 37 ${ }^{\circ} \mathrm{C}$. Following incubation, MTT $\left(5 \mathrm{mg} \mathrm{mL}^{-1}\right)$ was added into each well. Insoluble formazan was then dissolved in DMSO and absorbance was recorded at $570 \mathrm{~nm}$ using a microtiter plate reader. Cell viability was determined using the following formula:

$$
\text { Cell viability }(\%)=\frac{A_{\text {tratment }}-A_{\text {blank }}}{A_{\text {control }}-A_{\text {blank }}} \times 100
$$




\section{Apoptosis assay}

The apoptosis assay was carried out based on the procedures described by Maioral et al. (2013) with modifications (23). The K562, U937, Jurkat cells and PBMC were seeded as 1 $\times 10^{6}$ cells in 6-well plates and exposed to cyclophosphamide at a concentration of 28700 $\mu \mathrm{M}$ and ANXA1 at concentrations of $0.5,2.5$ and $5 \mu \mathrm{M}$, with an additional concentration of $25 \mu \mathrm{M}$ for Jurkat cells, and incubated at $37^{\circ} \mathrm{C}$ for $24 \mathrm{~h}$. The cells were washed with cold PBS and re-suspended in annexin V binding buffer. AnnexinV-FITC dye and PI were added to the cells and analyzed using a flow cytometer (BD FacsCanto II, CA, USA).

\section{Cell cycle analysis}

The cell cycle analysis assay was performed by flow cytometry following the method described by Maioral et al. (2013) with minor modifications (23). Briefly, the cells were seeded at $1 \times 10^{6}$ cells in 6-well plates and were exposed to cyclophosphamide and ANXA1 at concentrations of $28700 \mu \mathrm{M}$ and $2.5 \mu \mathrm{M}$, respectively, and incubated at $37^{\circ} \mathrm{C}$ for $24 \mathrm{~h}$. Cell cycle profiles were evaluated by staining DNA with PI using a BD Cycletest ${ }^{\mathrm{TM}}$ Plus DNA Reagent Kit according to the supplied protocol. Samples were analyzed with a flow cytometer (BD FacsCanto II, CA, USA) and ModFit LT cell cycle analysis software (ModFit LT, ME, USA).

\section{Statistical analysis}

Results were presented as mean \pm S.E.M. from three independent experiments. Data were analyzed using One Way ANOVA followed by Bonferroni's post-hoc test employing the GraphPad Prism 5 software (CA, USA). Differences between groups were considered significant if $p \leq 0.05$ and were marked as follows: ${ }^{* *}(p \leq 0.001),{ }^{* *}(p \leq 0.01)$ and ${ }^{*}(p \leq 0.05)$.

\section{RESULTS AND DISCUSSION}

Concentration of total endogenous ANXA1 in all three cell lines and PBMC, extracellular, membrane-bound and intracellular ANXA1, was quantified using the ELISA meth-

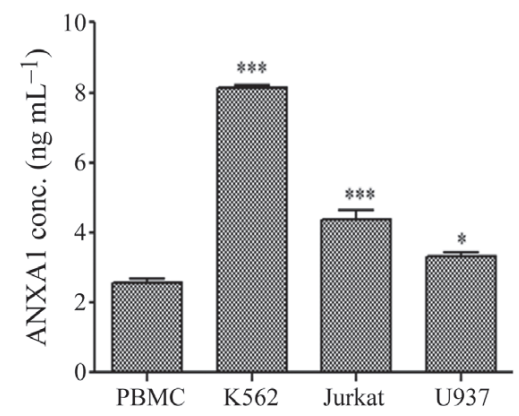

Fig. 1. Quantification of total endogenous ANXA1 in the three tested cell lines and PBMCs. ${ }^{*} p \leq 0.05$, *** $p \leq 0.001$ significant difference compared to PBMC. 
od. Total endogenous ANXA1 levels in all three cell lines and PBMC are given in Fig. 1. In the current study, the levels of total endogenous ANXA1 were shown to be significantly higher in the three tested leukemic cell lines compared to PBMC. Concentrations of total endogenous ANXA1 concentrations in K562 (8.15 $\left.\pm 0.04 \mathrm{ng} \mathrm{mL}^{-1}\right)$ and Jurkat $(4.37 \pm 0.25 \mathrm{ng}$ $\left.\mathrm{mL}^{-1}\right)$ cells were significantly higher $(p \leq 0.001)$ compared to the PBMC $\left(2.57 \pm 0.13 \mathrm{ng} \mathrm{mL}^{-1}\right)$. U937 cells also had a significantly higher ANXA1 concentration $\left(3.34 \pm 0.11 \mathrm{ng} \mathrm{mL}^{-1}, p \leq\right.$ $0.05)$ compared to the PBMCs, but significantly lower than the K562 $(p \leq 0.001)$ and Jurkat $(p \leq 0.01)$ cells. This is in accord with the proteomic study by Luczak et al. (2012), which
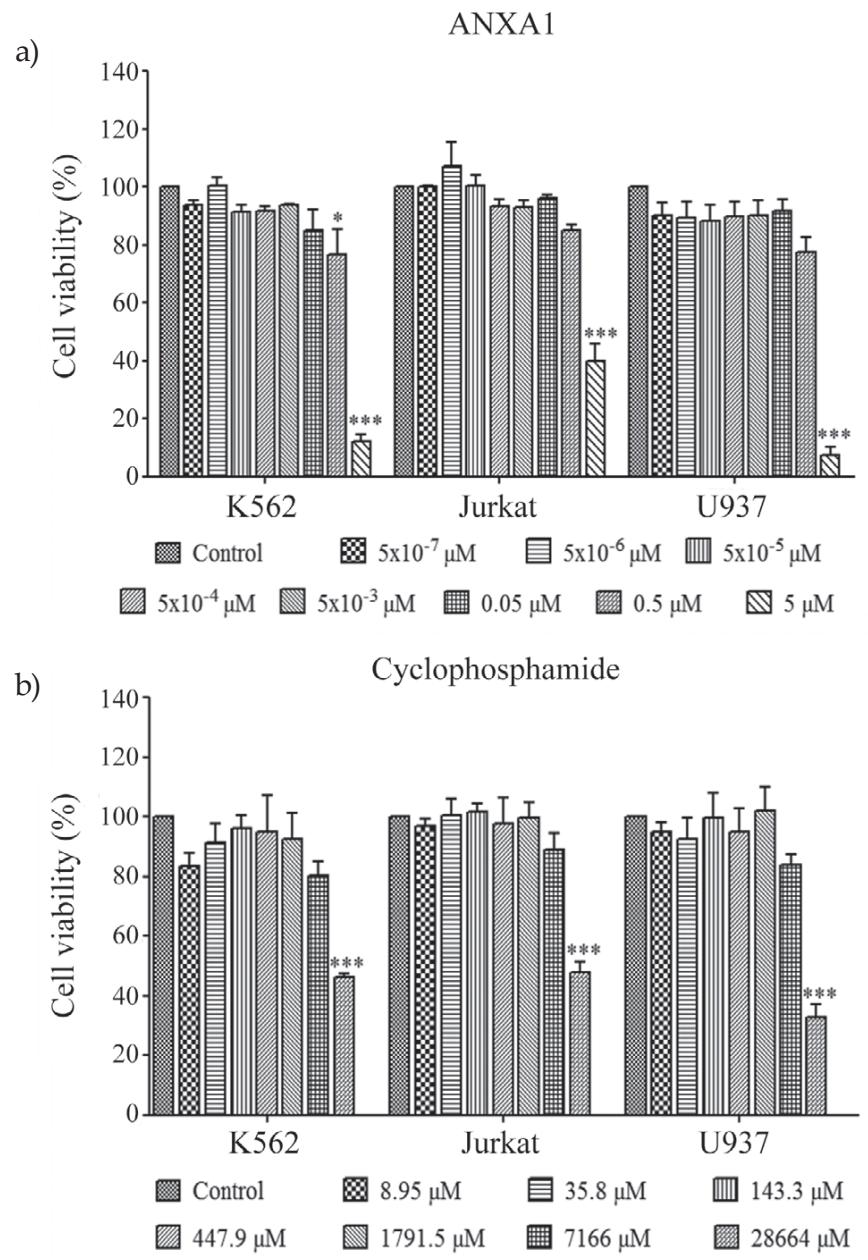

Fig. 2. Effect of a) ANXA1 and b) cylophosphamide treatment on cell viability in K562, Jurkat and U937 cell lines. a) K562, Jurkat and U937 were treated with ANXA1 in the 0-5 $\mu \mathrm{M}$ concentration range, b) K562, Jurkat and U937 were treated with cyclophosphamide in the concentration range $0-28700 \mu \mathrm{M}$. ${ }^{*} p \leq 0.05,{ }^{* * *} p \leq 0.001$ significant difference compared to the negative control (untreated cells). 
showed that ANXA1 can be used as a biomarker to differentiate between acute myeloid leukemia and healthy individuals (24).

Viability of the K562, Jurkat and U937 cells against ANXA1 was evaluated using MTT after a 24-h treatment. Fig. 2 shows the gradual decline in cell viability in the presence of increasing concentrations of ANXA1 (Fig. 2a) and cyclophosphamide (Fig. 2b). Sharp reductions were observed from concentrations 0.5 to $5 \mu \mathrm{M}$ in each cell line tested. At $5 \mu \mathrm{M}$ of ANXA1 treatment, all cell lines showed less than $50 \%$ viability. U937 cells showed the highest sensitivity to ANXA1 treatment with cell viability decreased to $7.51 \pm 2.74 \%$ post administration. K562 cells also showed remarkable sensitivity towards ANXA1 treatment (12.17 $\pm 2.45 \%$ viable cells) compared to Jurkat cells, which showed the highest $(p \leq 0.05)$ resistance to ANXA1 treatment (39.85 $\pm 5.94 \%$ viable cells). Cyclophosphamide was used in different ranges from ANXA1 based on the sensitivity of cells. Treatment with cyclophosphamide resulted in a significant decrease in viability of all cell lines at a concentration of $28700 \mu \mathrm{M}$. However, the $I C_{50}$ value of cyclophosphamide did not differ significantly between the cell lines (Table I). Therefore, cyclophosphamide, at the $28700 \mu \mathrm{M}$ concentration, was used as a positive control in the assays below.

Apoptosis is an essential, highly conserved, and tightly regulated cellular process of cell death, which is important for the development, host defense, and suppression of malignant transformation and inflammatory processes (25). Flow cytometric analysis by dual staining with Annexin V-FITC and propidium iodide of the cell lines and PBMC treated with ANXA1 was used to determine the percentage of apoptotic and necrotic cells. The results demonstrated that ANXA1 treatment enhanced apoptosis in leukemic cell lines. Percentage of apoptosis by ANXA1 in leukemic cell lines increased in a dose-dependent
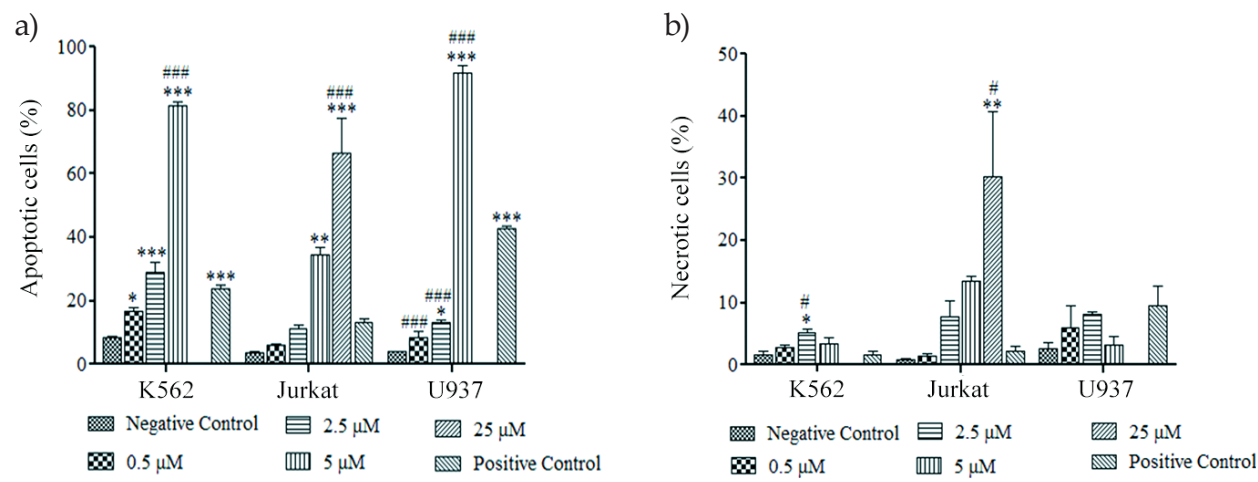

Fig. 3. Effect of ANXA1 treatment on apoptosis and necrosis of K562, Jurkat, U937 cells and PBMC. Cells were stained with Annexin V-FITC and propidium iodide before being quantified by flow cytometry. a) Percentage of apoptotic and b) necrotic cells of leukemic cell lines after a 24-h treatment with positive control (cyclophosphamide at $28700 \mu \mathrm{M}$ concentration) and ANXA1 at concentrations of $0.5,2.5$ and $5 \mu \mathrm{M}$ with additional $25 \mu \mathrm{M}$ for Jurkat cells, c) dot plots of forward-angle light scatter (FSC) vs. side-angle light scatter (SSC) of leukemic cell lines treated with positive control and ANXA1 at $2.5 \mu \mathrm{M}$ concentration for $24 \mathrm{~h}$. Dot plots were divided into four quadrants to indicate necrotic (Q1), late apoptotic (Q2), viable (Q3) and early apoptotic (Q4). ${ }^{*} p \leq 0.05,{ }^{* *} p \leq 0.01$, ${ }^{* * *} p \leq 0.001$ significant difference compared to the negative control. \#p $\leq 0.05$, \# $p \leq 0.01$, \#\# $p \leq 0.001$ significant difference compared to the positive control. 
c)

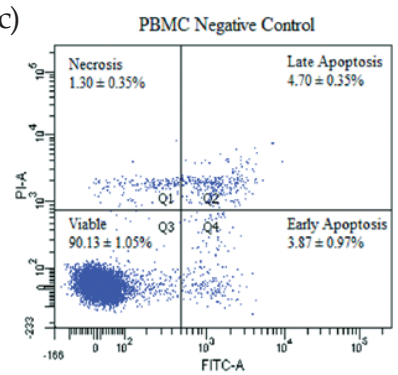

K562 Negative Control
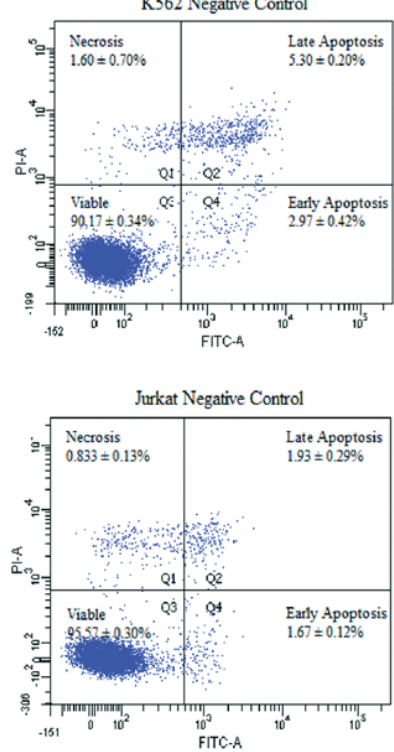

U937 Negative Control

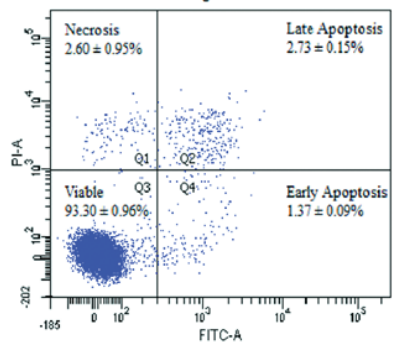

$\mathrm{PBMC}+\mathrm{ANXA1}$

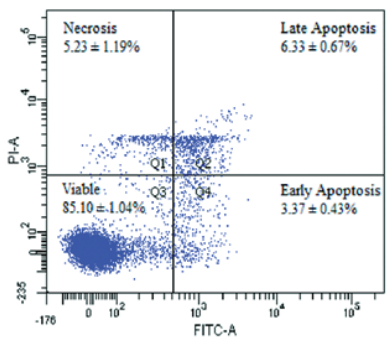

K562 + ANXA1
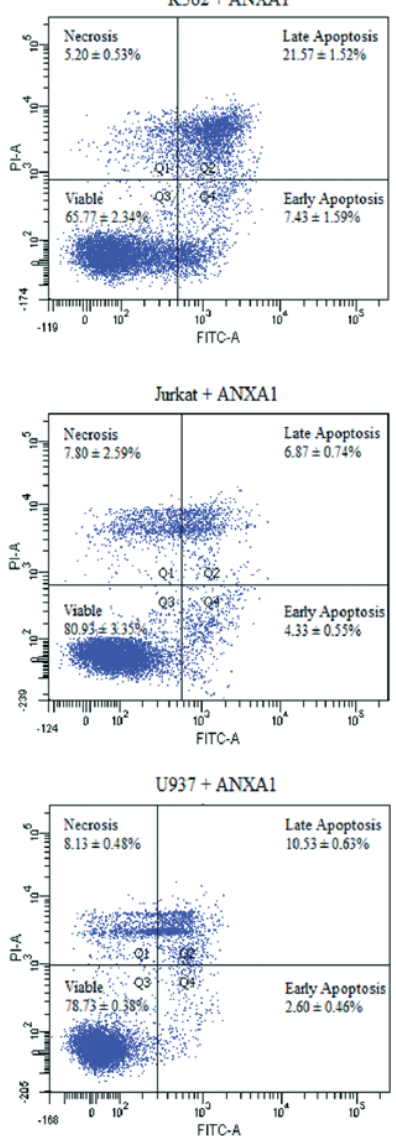

PBMC + Positive Control

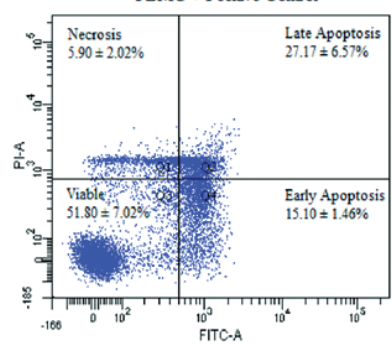

K562 + Positive Control
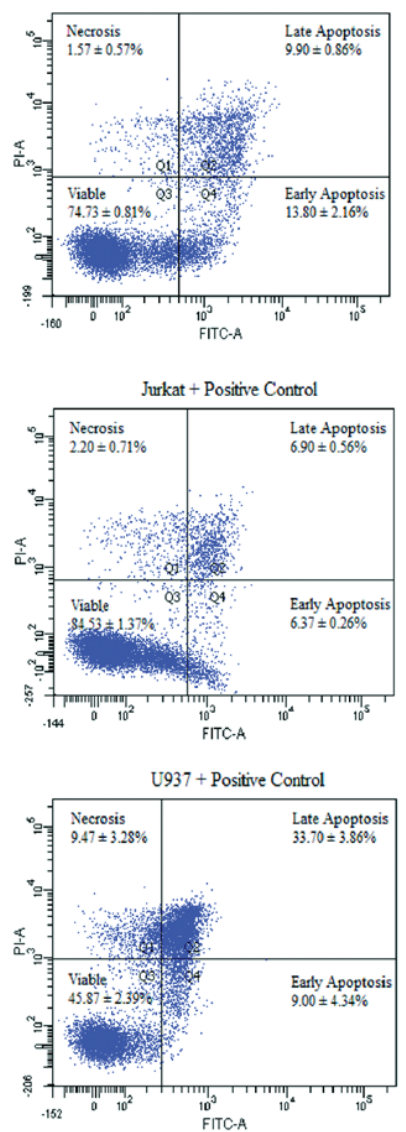

Fig. 3. Continued.

manner where the optimal apoptosis was detected at $2.5 \mu \mathrm{M}$ of ANXA1 onwards (Fig. 3). Apoptosis by cyclophosphamide in the positive control was best at the concentration of $28700 \mu \mathrm{M}$. 
The level of significance in apoptosis due to ANXA1 treatment reached up to $p \leq 0.001$ for K562 and $p \leq 0.05$ for U937 cells compared to their respective negative controls, while no significant apoptosis induction was observed in either Jurkat cells or PBMC. These results were in accord with the MTT results, which demonstrated that Jurkat cells were more resistant to ANXA1 treatment. Significant necrosis $(p \leq 0.05)$ was observed only in K562 cell lines. The $E C_{50}$ value of ANXA1 apoptosis induction in Jurkat cells, $17.0 \mu \mathrm{M}$, was also higher $(p \leq 0.05)$ compared to K562 $(3.6 \mu \mathrm{M})$ and U937 cells $(3.8 \mu \mathrm{M})$. It has been reported that enhanced ANXA1 level influences caspase 3 and caspase 9 signaling, which is of importance for the apoptosis pathway $(26,27)$. Caspases are members of cysteine protease where their activation will induce apoptosis in diverse cell types, including cancer cells (28). Increase in ANXA1 level results in a decrease in the bcl-2 level, a protein that functions to promote cell survival and prevent apoptosis $(26,27)$. COX-2 over-expression, on the other hand, can lead to an increase in bcl-2 expression, preventing the mitochondria from releasing cytochrome $c$ and subsequently inhibiting apoptosis (29). COX-2 also decreases the caspase activation, preventing apoptosis. Previous studies have shown that ANXA1 was able to inhibit COX-2 activities (17). A study by Ferreira et al. (1997) showed
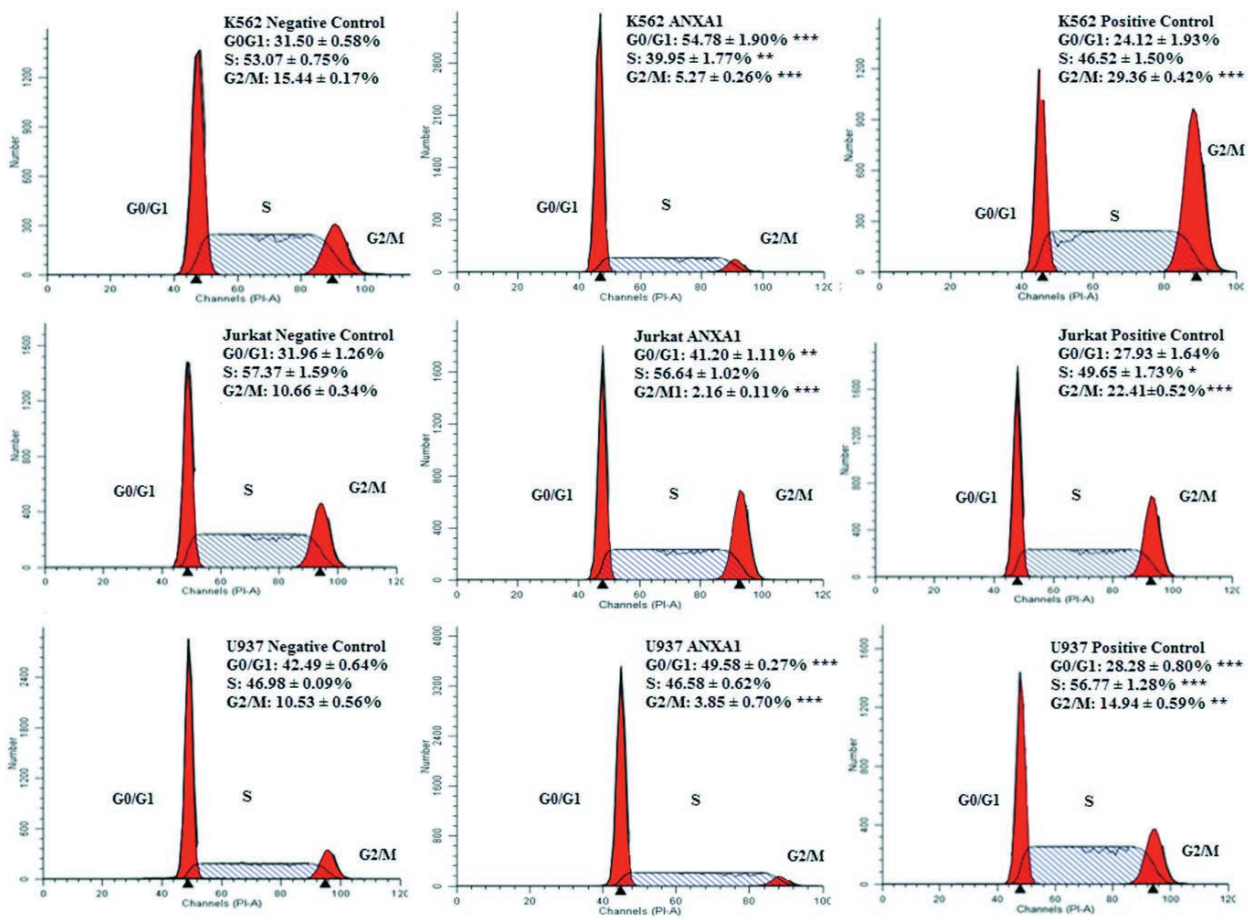

Fig. 4. Flow cytometric analysis of cell cycle distribution. Tested leukemic cell lines were treated with $2.5 \mu \mathrm{M}$ ANXA1 and positive control (cyclophosphamide $28700 \mu \mathrm{M}$ ). Each histogram depicts the cell cycle distribution of each cell line with the percentage of cells in G0/G1, S and G2/M phases. Data were gated to exclude apoptotic cells for these calculations. ${ }^{*} p \leq 0.05,{ }^{* *} p \leq 0.01,{ }^{* * *} p \leq 0.001$ significant difference compared to the negative control. 
that ANXA1 inhibited COX-2 activities in the J774 murine macrophage-like cell line (30). In addition, COX-2 has also been shown to play a role in inhibiting leukemic cell apoptosis $(30,31)$. Taken together, these previous findings suggested that it is possible for ANXA1 to induce apoptosis in leukemic cells by decreasing COX-2 expression, leading to a decrease in bcl-2 expression and activating apoptosis, either via its intrinsic or extrinsic pathway. However, the exact mechanism by which ANXA1 induces apoptosis needs to be further explored. Our study showed that the Jurkat cell was more resistant to ANXA1 treatment compared to K562 and U937 cells. Differences in cell type because of which Jurkat cells are of lymphoblastic origin and K562 and U937 cells are of myeloid origin could be the possible factor.

Significant apoptosis $(p \leq 0.001)$ was detected in cyclophosphamide treated cells at a concentration of $28700 \mu \mathrm{M}$ for both K562 and U937 cell lines compared to their respective negative controls. In contrast to ANXA1, cyclophosphamide induced significant apoptosis $(p \leq 0.01)$ in PBMC. However, at this concentration, no significant apoptosis was detected in Jurkat cells. In addition, no significant necrosis was observed at this concentration in any of the cell lines or PBMC. Among all the cell lines, U937 showed the highest sensitivity to cyclophosphamide treatment, followed by K562 and Jurkat cells. Cyclophosphamide treatment induced U937 cells to enter a late apoptotic stage, whereas in PBMC, K562 and Jurkat cells, no significant difference was observed in early and late apoptotic cell percentages. The $E C_{50}$ value of cyclophosphamide could only be determined in U937 cells (40660 $\mu \mathrm{M})$.

One of the main characteristics of cancer cells is the deregulated cell cycle that produces uncontrollable cell growth $(3,4,32)$. The eukaryotic cell cycle is regulated through activation and inactivation of cyclin-dependent kinases (CDKs), cyclin, and tumor suppressor protein $(32,33)$. Numerous chemotherapeutic agents target the cell cycle by interfering with the signal transduction pathways, affecting the DNA synthesis and causing the cell cycle to halt at certain stages (1).

To investigate the influence of ANXA1 on the cell cycle distribution of K562, Jurkat and U937 cells, flow cytometric analyses based on propidium iodide stained nuclei cells were performed. Representative flow histograms depicting cell cycle distribution of K562, Jurkat and U937 cells following a $24 \mathrm{~h}$ exposure to media (negative control), ANXA1 (2.5 $\mu \mathrm{M}$ ) and cyclophsophamide (positive control) are shown in Fig. 4. The results demonstrated that ANXA1 caused significant cell cycle arrest in the G0/G1 phase in Jurkat cells $(p \leq 0.01)$ and $\mathrm{U} 937(p \leq 0.001)$, with significant reduction of $\mathrm{G} 2 / \mathrm{M}$ phase $(p \leq 0.001)$ for both cell lines. In K562, the G0/G1 phase arrest $(p \leq 0.001)$ was compensated by a significant reduction in both $S(p \leq 0.01)$ and $\mathrm{G} 2 / \mathrm{M}$ phases $(p \leq 0.001)$ compared to their respective negative controls. Thus, ANXA1-mediated apoptosis induction in both K562 and U937 cells was suggested to be correlated with the G0/G1 phase cell cycle arrest. Cell cycle progression from the G1 phase to $S$ phase requires CDK-cyclin complexes between CDK and cyclin D, $\mathrm{E}$ and $\mathrm{A}(32,33)$. Growth arrest in the G0/G1 phase may be due to inhibition of CDK-cyclin complex activity (31). This inhibition prevents the phosphorylation of retinoblastoma tumor suppressor protein ( $\mathrm{pRB})$, which inhibits the binding of $\mathrm{pRB}$ to transcription factors E2F, halting the cell cycle progression into the $S$ phase and thus causing arrest in the G0/ G1 phase (31-33). Other than pRB, the tumor suppressor protein, p53, also plays a major role in regulating the cycle progression from the G0/G1 phase to the $S$ phase. Previous studies have shown that accumulation of this protein increases expression of the cyclin- 
CDK complex inhibitor protein, p21. According to Weinberg (2014), the increase in p53 expression induces both apoptosis and cell cycle arrest (34). Hence, it may be assumed that ANXA1 induces apoptosis and cycle arrest by increasing the p53 expression.

The positive control, cyclophosphamide treatment, showed a significant $(p \leq 0.001)$ cycle arrest in the G2/M phase in K562 and Jurkat cells. No significant reduction was detected in either G0/G1 or S phase in K562, while significant reduction $(p \leq 0.05)$ of cell percentage in the $\mathrm{S}$ phase was observed in Jurkat cells compared to their negative control. Cyclophosphamide significantly increased cell percentage of U937 in both S phase ( $p \leq$ $0.001)$ and $\mathrm{G} 2 / \mathrm{M}$ phase $(p \leq 0.01)$, with a significant reduction $(p \leq 0.001)$ in the G0/G1 phase. The PBMC cell cycle stages could not be analyzed in vitro as the samples were of peripheral location and PBMC could only proliferate unstimulated in the bone marrow.

\section{CONCLUSIONS}

In conclusion, ANXA1 at $2.5 \mu \mathrm{M}$ could induce both apoptosis and cell cycle arrests in the G0/G1 phase in K562 and U937 cell lines. However, a higher concentration of ANXA1 is required to achieve both effects in Jurkat cells. Based on the $\mathrm{EC}_{50}$ values, U937 cells were the most sensitive to ANXA1 treatment, followed by K562 and Jurkat. PBMC was not affected by ANXA1 at this concentration. Cyclophosphamide could only show a similar pattern to the ANXA1 in K562 and Jurkat cells but required a significantly higher concentration compared to ANXA1.

Acknowledgments. - This study was funded by the Ministry of Science, Technology and Innovation (MOSTI) under No: 06-01-02-SF1053. The authors thank the Faculty of Health Science, UKM, for the use of the flow cytometer.

\section{REFERENCES}

1. W. J. Liu, T. Zhang, Q. L. Guo, C. Y. Liu and Y. Q. Bai, Effect of ATRA on the expression of HOXA5 gene in K562 cells and its relationship with cell cycle and apoptosis, Mol. Med. Rep. 13 (2016) 4221-4228; 10.3892/mmr.2016.5086

2. K. Yata, Y. Sadahira, T. Otsuki, H. Sakaguchi, Y. Isozaki and M. Uno, Cell cycle analysis and expression of cell cycle regulator genes in myeloma cells overexpressing cyclin D1, Br. J. Haematol. 114 (2001) 591-599.

3. B. T. Gjertsen and H. Wiig, Investigation of therapy resistance mechanisms in myeloid leukemia by protein profiling of bone marrow extracellular fluid, Expert Rev. Proteomics 9 (2012) 595-598; https://doi.org/10.1586/epr.12.55

4. W. Ni, W. Qian and X. Tong, Cryptotanshinone induces apoptosis of HL-60 cells via mitochondrial pathway, Trop. J. Pharm. Res. 13 (2014) 545-551.

5. S. Agrawal, M. Unterberg, S. Koschmieder, U. zur Stadt, U. Brunnberg, W. Verbeek, T. Büchner, W. E. Berdel, H. Serve and C. Müller-Tidow, DNA methylation of tumor suppressor genes in clinical remission predicts the relapse risk in acute myeloid leukemia, Cancer Res. 67 (2007) 13701377; https://doi.org/10.1158/0008-5472.CAN-06-1681

6. Q. Y. Lu, Y. S. Jin, Z. F. Zhang, A. D. Le, D. Heber, F. P. Li, S. M. Dubinett and J. Y. Rao, Green tea induces annexin-I expression in human lung adenocarcinoma A549 cells: involvement of annexin-I in actin remodeling, Lab. Investig. 87 (2007) 456-465; http://doi.org/10.1038/labinvest.3700534 
7. S. H. Xia, L. P. Hu, H. Hu, W. T. Ying, X. Xu, Y. Cai, Y. L. Han, B. S. Chen, F. Wei, X. H. Qian, Y. Y. Cai, Y. Shen, M. Wu and M. R. Wang, Three isoforms of annexin I are preferentially expressed in normal esophageal epithelia but down-regulated in esophageal squamous cell carcinomas, Oncogene 21 (2002) 6641-6648

8. R. Luthra, R. R. Singh , M. G. Luthra, Y. X. Li, C. Hannah, A. M. Romans, B. A. Barkoh, S. S. Chen, J. Enros, D. M. Maru, R. R. Boraddus, A. Rashid and C. T. Albarracin, MicroRNA-196a targets annexin A1: a microRNA-mediated mechanism of annexin A1 downregulation in cancers, Oncogene 27 (2008) 6667-6678; https://doi.org/10.1038/onc.2008.256

9. R. Duncan, B. Carpenter, L. C. Main, C. Telfer and G. I. Murray, Characterisation and protein expression profiling of annexins in colorectal cancer, Br. J. Cancer. 98 (2008) 426-433; https://doi. org/10.1038/sj.bjc.6604128

10. R. Belvedere, V. Bizzarro, G. Forte, F. D. Piaz, L. Parente and A. Petrella, Annexin A1 contributes to pancreatic cancer cell phenotype, behaviour and metastatic potential independently of formyl peptide receptor pathway, Sci. Reports 6 (2016) 1-14.

11. W. Ahmad, E. Kumolosasi, I. Jantan, M. Jasamai and E. Salim, Modulatory effect of phytoestrogens and curcumin on induction of annexin 1 in human peripheral blood mononuclear cells and their inhibitory effect on secretory phospholipase $\mathrm{A}_{2}$, Trop. J. Pharm. Res. 13 (2014) 171-177; https:// doi.org/10.4314/tjpr.v13i2.1

12. L. Parente and E. Solito, Annexin 1: More than an anti-phospholipase protein, Inflamm. Res. 53 (2004) 125-132; https://doi.org/10.1007/s00011-003-1235-z

13. L. H. K. Lim and S. Pervaiz, Annexin 1 : the new face of an old molecule, FASEB J. 24 (2007) 968975; https://doi.org/10.1096/fj.06-7464rev

14. C. Guo, S. Liu and M-Z. Sun, Potential role of Anxa1 in cancer, Futur. Oncol. 9 (2013) 1773-1793; https://doi.org/10.2217/fon.13.114

15. S. Canaider, E. Solito, C. de Coupade, R. J, Flower, F. Russo-Marie, N. J. Goulding and M. Peretti, Increased apoptosis in U937 cells over-expressing lipocortin 1 (Annexin I), Life Sci. 66 (2000) PL265-PL270

16. E. Solito E, C. De Coupade, S. Canaider, N. J. Goulding and M. Perretti, Transfection of annexin 1 in monocytic cells produces a high degree of spontaneous and stimulated apoptosis associated with caspase-3 activation, Br. J. Pharmacol. 13 (2001) 217-228; https://doi.org/10.1038/sj.bjp.0704054

17. F. Hirata, Molecular targets, cancer chemoprevention, and dietary phytochemicals: Nuclear annexin A1 as a promising new molecular target of cancer chemoprevention, Austin J. Pharmacol. Ther. 2 (2014) 2-3.

18. A. Petrella, C. W. D'Acunto, M. Rodriquez, M. Festa, A, Tosco, I. Bruno, S. Terracciano, M. Taddei, L. G. Paloma and L. Parente, Effects of FR235222, a novel HDAC inhibitor, in proliferation and apoptosis of human leukaemia cell lines: Role of annexin, Eur. J. Cancer. 44 (2008) 740-749; https:// doi.org/10.1016/j.ejca.2008.01.023

19. C. L. Rackham, A. E. Vargas, R. G. Hawkes, S. Amisten, S. J. Persaud, A. L. Austin, A. J. King and P. M. Jones, Annexin A1 is a key modulator of mesenchymal stromal cell-mediated improvements in islet function, Diabetes 65 (2016) 129-139; https://doi.org/10.2337/db15-0990

20. G. S. D. Purvis, F. Chiazza, J. Chen, R. Azevedo-Loiola, K. Martin, D. H. M. Kusters, C. C. Reutelingsperger, N. Fountoulakis, L. Gnudi, M. M. Yaqoob, M. Collino, C. Thiemermann and E. Solito, Annexin A1 attenuates microvascular complications through restoration of Akt signalling in a murine model of type 1 diabetes, Diabetologia 61 (2018) 482-495; https://doi.org/10.1007/s00125-0174469-y

21. E. Cristante, S. McArthur, C. Mauro, E. Maggioli, I. A. Romero, M. Wylezinska-Arridge, P. O. Couraud, J. lopez-Tremoleda, H. C. Christian, B. B. Weksler, A. Malaspina and E. Solito, Identification of an essential endogenous regulator of blood-brain barrier integrity, and its pathological and 
therapeutic implications, Proc. Natl. Acad. Sci. USA 110 (2012) 832-841; https://doi.org/10.1073/ pnas.1209362110

22. M. Ries, R. Loiola, U. N. Shah, S. M. Gentleman, E. Solito and M. Sastre, The anti-inflammatory Annexin A1 induces the clearance and degradation of the amyloid- $\beta$ peptide, J. Neuroinflammation (2016) 1-15; https://doi.org/10.1186/s12974-016-0692-6

23. M. F. Maioral, P. C. Gaspar, G. R. Rosa Souza, A. Mascarello, L. D. Chiaradia, M. A. Licínio, A. C. Moraes, R. A. Yunes, R. J. Nunes and M. C. Santos-Silva, Apoptotic events induced by synthetic naphthylchalcones in human acute leukemia cell lines, Biochimie 95 (2013) 866-874; https://doi. org/10.1016/j.biochi.2012.12.001

24. M. Luczak, M. Kaźmierczak, L. Handschuh, K. Lewandowski, M. Komarnicki and M. Figlerowicz, Comparative proteome analysis of acute myeloid leukemia with and without maturation, $J$. Proteomics 75 (2012) 5734-5748; https://doi.org/10.1016/j.jprot.2012.07.030

25. R. Debret, H. El Btaouri, L. Duca, I. Rahman, S. Radke, B. Haye, J. M. Sallenave and F. Antonicelli, Annexin A1 processing is associated with caspase-dependent apoptosis in BZR cells, FEBS Lett. 546 (2003) 195-202.

26. J. P. Vago, C. R. Nogueira, L. P. Tavares, F. M. Soriani, F. Lopes, R. C. Russo, V. Pinho, M. M. Teixeira and L. P. Sousa, Annexin A1 modulates natural and glucocorticoid-induced resolution of inflammation by enhancing neutrophil apoptosis, J. Leukoc. Biol. 92 (2012) 249-258; http://doi. org/10.1189/jlb.0112008

27. G. Li, S. He, L. Chang, H. Lu, H. Zhang, H. Zhang and J. Chiu, GADD45 $\alpha$ and annexin A1 are involved in the apoptosis of HL-60 induced by resveratrol, Phytomedicine 18 (2011) 704-709; https:// doi.org/10.1016/j.phymed.2010.11.015

28. R. N. Winter, A. Kramer, A. Borkowski and N. Kyprianou, Loss of caspase-1 and caspase-3 protein expression in human prostate cancer, Cancer Res. 61 (2001) 1227-1232.

29. T. C. Reddy, D. B. Reddy, A. Aparna, K. M. Arunasree, G. Gupta, C. Achari, G. V. Reddy, V. Lakshmipathi, A. Subramanyam and P. Reddanna, Anti-leukemic effects of gallic acid on human leukemia K562 cells: downregulation of COX-2, inhibition of BCR/ABL kinase and NF-kB inactivation, Toxicol. In Vitro 26 (2012) 396-405; https://doi.org/10.1016/j.tiv.2011.12.018

30. S. H. Ferreira, F. Q. Cunha, B. B. Lorenzetti, M. A. Michelin, M. Perretti, R. J. Flower and S. Poole, Role of lipocortin-1 in the anti-hyperalgesic actions of dexamethasone, Br. J. Pharmacol. 121 (1997) 883-888; https://doi.org/10.1038/sj.bjp.0701211

31. Y. Nakanishi, R. Kamijo, K. Takizawa, M. Hatori and M. Nagumo, Inhibitors of cyclooxygenase-2 (COX-2) suppressed the proliferation and differentiation of human leukaemia cell lines, Eur. J. Cancer. 37 (2001) 1570-1578.

32. A. M. Saleh, A. Aljada, M. M. El-Abadelah, M. O. Taha, S. S. Sabri, J. A. Zahra and M. A. Aziz, The anticancer activity of the substituted pyridone-annelated isoindigo $\left(5^{\prime}-\mathrm{Cl}\right)$ involves G0/G1 cell cycle arrest and inactivation of CDKs in the promyelocytic leukemia cell line HL-60, Cell Physiol. Biochem. 35 (2015) 1943-1957; https://doi.org/10.1159/000374003

33. Y. Nagahara, Y. Matsuoka, K. Saito, M. Ikekita, S. Higuchi and T. Shinomiya, Coordinate involvement of cell cycle arrest and apoptosis strengthen the effect of FTY720, Jap. J. Cancer Res. 92 (2001) 680-687.

34. R. A. Weinberg, p53 and Apoptosis: Master Guardian and Executioner, in The Biology of Cancer (Ed. R. A. Weinberg), 2nd ed, Garland Science, New York 2014. pp. 331-390. 